\title{
Absence of Thy- 1 results in TGF- $\beta$ induced MMP-9 expression and confers a profibrotic phenotype to human lung fibroblasts
}

\author{
Gustavo Ramírez ${ }^{1,4, *}$, James S Hagood ${ }^{2,3}$, Yan Sanders ${ }^{4}$, Remedios Ramírez ${ }^{1}$, Carina Becerril ${ }^{5}$, Lourdes Segura ${ }^{1}$, \\ Lourdes Barrera ${ }^{5}$, Moisés Selman ${ }^{5}$ and Annie Pardo ${ }^{1}$
}

Fibroblasts differ in a variety of phenotypic features, including the expression of Thy- 1 a glycophosphatidylinositol-linked glycoprotein. Fibroblasts in idiopathic pulmonary fibrosis (IPF) are Thy-1 negative, whereas most fibroblasts from normal lungs are Thy- 1 positive. However, the functional consequences of the absence of Thy-1 are not fully understood. We analyzed the expression of Thy-1 in several primary fibroblasts lines derived from IPF, hypersensitivity pneumonitis (HP), and normal human lungs. We found that a high proportion, independently of their origin, expressed Thy- 1 in vitro.

We identified a primary culture of HP fibroblasts, which did not express Thy-1, and compared several functional activities between Thy-1 (-) and Thy-1 ( + ) fibroblasts. Thy-1 (-) fibroblasts were smaller (length: $41.3 \pm 20.8 \mu$ versus $83.1 \pm 40 \mu$ ), showed increased proliferative capacity and enhanced PDGF-induced transmigration through collagen I (59.9\% versus $42.2 \%$ over control under basal conditions, $P<0.01$ ). Likewise, Thy-1 ( - ) fibroblasts either spontaneously or after TGF- $\beta$ stimulation demonstrated stronger contraction of collagen matrices (eg, $0.17 \pm 0.03$ versus $0.6 \pm 0.05 \mathrm{~cm}^{2}$ after TGF- $\beta$ stimulation at $24 \mathrm{~h} ; P<0.01$ ). Thy- 1 ( - ) lung fibroblasts stimulated with TGF- $\beta 1$ expressed MMP-9, an enzyme that is usually not produced by lung fibroblasts. TGF $\beta$-induced MMP-9 expression was reversible upon re-expression of Thy- 1 after transfection with full-length Thy-1. $\beta$-glycan, a TGF- $\beta$ receptor antagonist abolished MMP-9 expression. TGF- $\beta 1$-induced MMP-9 in Thy-1 (-) fibroblasts depended on the activation of ERK1/2 signaling pathway. Finally, we demonstrated that fibroblasts from IPF fibroblastic foci, which do not express Thy-1 exhibit strong staining for immunoreactive MMP-9 protein in vivo. These findings indicate that loss of Thy- 1 in human lung fibroblasts induces a fibrogenic phenotype.

Laboratory Investigation (2011) 91, 1206-1218; doi:10.1038/labinvest.2011.80; published online 16 May 2011

KEYWORDS: fibroblast; MMP; pulmonary fibrosis; Thy-1

Idiopathic pulmonary fibrosis (IPF) is a progressive and lethal disease of unknown etiology characterized by expansion of the fibroblast population, with transdifferentiation to myofibroblasts forming the so called fibroblast foci, and by the exaggerated accumulation of extracellular matrix with disruption of the normal lung architecture. ${ }^{1-3}$ The persistence of myofibroblasts, likely by resistance to apoptosis, has an important role in the propagation of fibrosis, with evolution to terminal end-stage fibrotic lung. ${ }^{4}$ Growing evidence indicates that the fibroblasts in fibrotic lungs differ from normal lung fibroblasts in a variety of phenotypic features, including surface markers, cytoskeletal composition, collagen synthesis, proliferative capacity, survival, transcriptional signature, and ribosome recruitment, among others. ${ }^{5-8}$

Particularly, it has been demonstrated that myofibroblasts in the fibroblast foci from individuals with IPF are Thy-1 negative, whereas most fibroblasts from normal lungs are Thy-1 positive, most likely resulting from epigenetic reprogramming. ${ }^{9,10}$ The absence of Thy- 1 induces a profibrotic, myofibroblastic, apoptosis-resistant phenotype in lung fibroblasts. ${ }^{11}$ In experimentally induced lung fibrosis, it has been shown that Thy-1-null mice exhibited increased TGFbeta activation and develop more extensive and severe fibrotic reaction than do wild-type mice. ${ }^{9}$ Thy- 1 or CD90 is a

\footnotetext{
${ }^{1}$ Facultad de Ciencias, Universidad Nacional Autónoma de México, México DF, México; ${ }^{2}$ University of California-San Diego, La Jolla, CA, USA; ${ }^{3}$ Rady Children's Hospital, San Diego, CA, USA; ${ }^{4}$ University of Alabama-Birmingham, Birmingham, AL, USA and ${ }^{5}$ Instituto Nacional de Enfermedades Respiratorias Ismael Cosío Villegas, México DF, México

Correspondence: Dr A Pardo, PhD, Facultad de Ciencias, Universidad Nacional Autónoma de México, México DF, México.

E-mail: apardos@unam.mx

${ }^{*}$ This work was submitted in partial fulfillment of the requirements to obtain the PhD degree at Universidad Nacional Autónoma de México. Received 9 August 2010; revised 3 January 2011; accepted 24 January 2011
} 
glycophosphatidylinositol-linked glycoprotein expressed on the surface of various cell types including fibroblasts. ${ }^{12}$ Thy- 1 activates multiple signaling pathways, affecting cell-cell and cell-extracellular matrix interactions, and influencing a variety of cellular functions including cell proliferation, differentiation, and survival. ${ }^{13}$ However, our knowledge of the effects of the absence of Thy-1 on fibroblast phenotype programming is still incomplete, and in particular the effects of Thy-1 expression on matrix metalloproteinases (MMPs) and ECM homeostasis have not been previously described. MMPs, primarily MMP-2 and MMP-9 are highly upregulated in IPF lungs, and have been implicated in the pathogenesis of IPF. ${ }^{14}$

In this study we analyze the profibrotic characteristics of a Thy-1-negative fibroblast line discovered in a study to evaluate the expression of Thy- 1 in several primary fibroblast cell lines obtained from human normal lungs and lungs from patients with IPF and hypersensitivity pneumonitis (HP). Findings from this cell line were confirmed in sorted human lung fibroblasts. Our results showed that Thy-1 (-) fibroblasts exhibit increased proliferative and migratory capacity and stronger contraction of collagen matrices compared with the Thy- $1(+)$ fibroblasts. Importantly, Thy-1 (-) fibroblasts stimulated with TGF- $\beta 1$ expressed MMP-9, an enzyme that is usually not synthesized by lung fibroblasts. This effect was reversed upon Thy- 1 transfection, and it was mediated by extracellular signalregulated kinase (ERK) activation.

\section{MATERIALS AND METHODS Lung Fibroblasts}

Fibroblasts were derived from lung tissue obtained from HP $(n=4)$ and IPF $(n=5)$ patients. Diagnosis of IPF and HP was carried out as described and confirmed by histopathology. ${ }^{15}$ Control fibroblasts $(n=3)$ were derived from lungs of patients undergoing lobectomy/pneumonectomy for removal of a primary lung tumor, from areas with no histologic evidence of disease. The protocol was approved by the Bioethics Committee at the Instituto Nacional de Enfermedades Respiratorias in Mexico DF. Lung fibroblasts were isolated by trypsin dispersion, and cells were grown in Ham's F-12 medium (GIBCO Laboratories, Grand Island, NY, USA) supplemented with $10 \%$ fetal bovine serum (FBS), $100 \mathrm{U} / \mathrm{ml}$ penicillin, and $100 \mathrm{~g} / \mathrm{ml}$ streptomycin (Invitrogen, Carlsbad, CA, USA) (E2). Fibroblasts (passages 5-9) were cultured at $37^{\circ} \mathrm{C}$ in $5 \% \mathrm{CO}_{2} / 95 \%$ air in $\mathrm{T}-25 \mathrm{~cm}^{2}$ flasks (Corning, New York, NY, USA).

For some experiments lung fibroblasts were serum starved for $24 \mathrm{~h}$ and stimulated with $5 \mathrm{ng} / \mathrm{ml}$ recombinant human TGF- $\beta 1$ (R\&D Systems, MN, USA). TGF- $\beta 1$ stimulated fibroblasts were pretreated with MEK-1/2 inhibitor PD98059 $(10 \mu \mathrm{M}$; Calbiochem-Novabiochem, San Diego CA, USA), and $\beta$-glycan ( $100 \mathrm{nM}$; a generous gift of Dr López-Casillas, Universidad Nacional Autónoma de México). ${ }^{16}$

\section{Flow Cytometry Analysis}

Cells were stained with anti-hThy-1-APC or anti-hThy-1FITC (Santa Cruz Biotechnology, CA, USA), conjugated monoclonal antibodies. Fibroblasts were incubated with the antibodies for $1 \mathrm{~h}$ at $4^{\circ} \mathrm{C}$, washed with PBS and fixed with $1 \%$ p-formaldehyde. Stained cells were analyzed by flow cytometry in a FACSAria with the FACSDiva software version 6.1 (BD Biosciences, San Jose, CA, USA).

\section{Southern Blot}

To establish a Thy-1 fingerprint, genomic DNA from Thy-1 $(+)$ and Thy-1 ( - ) fibroblasts was digested with HindIII and resolved by electrophoresis in $0.8 \%$ agarose. DNA was transferred to nylon membranes and was hybridized with a probe containing Thy- 1 fragment recovered from the recombinant plasmid pcDNA3.1 using EcoRI and NotI. The Thy-1 fragment was labeled by random primer extension with digoxigenin-11-dCTP. Immobilized DNA was hybridized overnight at $42^{\circ} \mathrm{C}$ with $10 \mathrm{ng}$ of Thy-1 probe per ml of hybridization buffer ( $10 \%$ dextran sulfate, $1 \%$ sodium dodecyl sulfate, $1 \mathrm{M} \mathrm{NaCl}, 100 \mathrm{ng}$ of salmon sperm DNA per $\mathrm{ml}$ ). Hybridization signals were detected with $\mathrm{x}$-ray radiography.

\section{Real-Time Quantitative RT-PCR}

Total RNA was extracted from lung fibroblasts using TRIzol reagent (Invitrogen Life Technologies, Grand Island, NY, USA). A measure of $1 \mu \mathrm{g}$ of total RNA was reverse transcribed cDNA using the iScript cDNA Synthesis Kit (Bio-Rad Laboratories, Hercules, CA, USA) according to the manufacturer's instructions. Real-time PCR amplification was performed using an i-Cycler iQ Detection System (Bio-Rad Laboratories), Taqman probe Hs00264235_s1 (Applied Biosystems, CA, USA) and 4352930E eukaryotic 18S rRNA that was used as endogenous control. Results from three different samples each in triplicate are expressed as mean \pm s.d. of the number of copies of the target gene normalized to $18 \mathrm{~S}$ rRNA.

Each cDNA was quantified in triplicate using a Mastermix solution (Applied Biosystems). Thermal cycling conditions were $95^{\circ} \mathrm{C}$ for $3 \mathrm{~min}, 40$ cycles of $95^{\circ} \mathrm{C}$ for $15 \mathrm{~s}$ and $60^{\circ} \mathrm{C}$ for $1 \mathrm{~min}$. A standard curve was built using a Thy-1 product of PCR on copy number serial dilutions in a dynamic range of $1 \times 10^{2}$ to $1 \times 10^{9}$.

PCR was also performed to detect Thy-1 using fibroblast genomic DNA using the Taqman probe.

\section{Western Blot}

Cells were lysed in RIPA buffer M-PER (Pierce, Cheshire, UK) containing a protease inhibitor cocktail (P8340; Sigma St Louis MO, USA). Protein concentrations were determined by Bradford method. Equal amounts of proteins $(30 \mu \mathrm{g})$ were resolved on SDS-PAGE in 12.5\% acrylamide gels and transferred to nitrocellulose (Bio-Rad Laboratories). After blocking with non-fat dried milk, the membranes were incubated with primary antibodies Thy-1 (1:10 000 dilution; Santa Cruz 
Biotechnology), ERK1/2 (1:2000 dilution; Calbiochem, San Diego, CA, USA) phosphorylated ERK1/2 (1:2000 dilution; Calbiochem), and $\beta$-tubulin (1:200 dilution; Santa Cruz Biotechnology) followed by horseradish peroxidase-labeled antibody. Immunodetection was performed by chemiluminescence using the Molecular Imager ChemiDoc XR + System and Quantity One software version 4.6.9 (Bio-rad Laboratories). Results were expressed as a ratio of band density to total $\beta$-tubulin.

\section{Immunocytochemistry and Immunohistochemistry}

Human fibroblasts were seeded on glass cover slips and treated as previously described. ${ }^{17}$ Cells were then incubated with primary monoclonal antibodies anti-procollagen-1 at (1:100 dilution; Chemicon Europe, Hampshire UK) and antiMMP-9 (1:700 dilution; Chemicon Temecula, CA, USA). The length of 100 Thy-1 (+) and 100 Thy-1 (-) cells were measured with the program Image-Pro Plus, version 4.0 for Windows, Media Cybernetics. For this purpose, several areas of the slide were photographed at $10 \times$ and the calibration measurement was adjusted to $100 \mu,(100 \mu=36.83)$.

Tissue sections from IPF and controls were treated as described. ${ }^{18}$ Antigen retrieval was carried out in citrate buffer $10 \mathrm{mM}, \mathrm{pH} 6.0$ for $6 \mathrm{~min}$ in a microwave. Samples were incubated with antiMMP-9 $(2.5 \mu \mathrm{g} / \mathrm{ml}$; Chemicon International) at $4{ }^{\circ} \mathrm{C}$ overnight. For cells and tissue sections after the primary antibody a secondary biotinylated anti-immunoglobulin followed by horseradish peroxidase-conjugated streptavidin (BioGenex, San Ramon, CA, USA) was used according to manufacturer instructions. 3-amino-9ethyl-carbazole (AEC, BioGenex) in acetate buffer containing $0.05 \% \mathrm{H} 2 \mathrm{O} 2$. The sections or cells were counterstained with hematoxylin. The primary antibody was replaced by nonimmune serum for negative controls. In addition, the lung specimen from the Thy-1 negative HP patient and from two HP patients were immunostained for Thy-1 using human anti-Thy-1 monoclonal antibody (Clone ID: EPR3133) Epitomics, Burlingame, CA, USA) at 1:50 dilution.

\section{Growth Rate Assay}

Fibroblasts were plated in 96-well culture plates at a cell density of $1.5 \times 10^{3}$ cells/well and synchronized with serumfree medium for $24 \mathrm{~h}$ and then replaced with Ham's F-12 medium supplemented with $1 \%$ FBS and the growth rate was followed every other day for 8 days using the cell proliferation reagent WST-1 (Roche, Mannheim, Germany) as previously described. ${ }^{5,17}$ Absorbance changes were taken as percentage of growth rate increase related to basal values.

\section{Migration Assay}

Migration of human lung fibroblasts was assayed using 24well collagen I-coated Boyden chambers (Chemicon) with an $8-\mu \mathrm{m}$ pore size. Fibroblasts $\left(3 \times 10^{5}\right.$ cells $)$ were added to the upper chamber and the lower chamber contained $0.3 \mathrm{ml}$ of medium with PDGF-BB (20 ng/ml; R\&D Systems). After incubation for $8 \mathrm{~h}$ at $37^{\circ} \mathrm{C}$ the non-migrating cells on the top of the chamber were scraped and washed. The migrating cells were quantified according to manufacturer's instructions as described. ${ }^{19}$ Briefly, the cells were stained and the color eluted with $300 \mu \mathrm{l}$ of extraction buffer, and $150-\mu \mathrm{l}$ aliquots were measured in an ELISA plate reader at $545 \mathrm{~nm}$. All assays were carried out in duplicate.

\section{Wound Healing Scratch Assay}

Human fibroblasts were seeded onto six-well plates (Corning) at $2.5 \times 10^{4}$ cells/well with $3 \mathrm{ml}$ of medium F12 with $10 \%$ FBS. At 2 days, the monolayers were mechanically disrupted with a sterile $200 \mu \mathrm{l}$ tip. The assay was performed for duplicate. The wells were photographed every $12 \mathrm{~h}$.

\section{Collagen Matrix Contraction Assay}

To determine the contractile capacity of fibroblasts, an in vitro floating collagen matrix contraction model was used. Briefly, Thy- $1(+)$ and Thy- $1(-)$ fibroblasts $\left(2 \times 10^{5}\right.$ cells/ $\mathrm{ml})$ were added to a $\mathrm{pH} 7.4$ collagen solution $(2 \mathrm{mg} / \mathrm{ml}$; INAMED; Fremont, CA, USA) and $0.5 \mathrm{ml}$ were plated per well in a 24-well culture plate. Plates were incubated for $2 \mathrm{~h}$ at $37^{\circ} \mathrm{C}$, which caused polymerization of collagen cell lattices. After $2 \mathrm{~h}$, the gels were detached from the walls with a thin sterile spatula. Finally, $0.5 \mathrm{ml}$ of serum-free F12 culture medium was applied with or without TGF- $\beta$. Each condition was performed in duplicate. Contraction of the gel was photographed and measured using a Kodak image analysis system.

\section{Gelatin Zymography}

Conditioned media (CM) were collected from fibroblasts grown under basal conditions and stimulated with TGF- $\beta$ ( $5 \mathrm{ng} / \mathrm{ml})$. In some experiments $\beta$-glycan $(100 \mathrm{nM})$, was added 30 min before TGF- $\beta$ stimulation. Briefly, samples were mixed with an equal volume of $2 \mathrm{X}$ sample buffer, resolved under non-reducing conditions on 10\% SDS-PAGE containing $1 \mathrm{mg} / \mathrm{ml}$ gelatin as a substrate. CM from human lung fibroblasts and from U2-OS cells stimulated with PMA was used as MMP-2 and MMP-9 positive controls, respectively. ${ }^{15}$

\section{Lung Fibroblasts Transfection and Sorting}

Thy-1 (-) human lung fibroblasts were cultured in F-12 media containing $10 \%$ FBS and $1 \%$ penicillin/streptomycin. Fibroblasts were transfected with the mammalian expression vector pcDNA3.1 Zeo containing the full-length human Thy-1 cDNA or empty vector using a nucleoporator device and Lung Fibroblast Transfection reagent (AMAXA Biosystems, Gaithersburg, MD, USA). Cells were sorted on the basis of expression of Thy-1 by FACS using a FACS Calibur cytometer (BD Biosciences). Thy-1 (+) transfected cells (>95\%) and Thy-1 (-) sub-population cultures were seed in a plate for post-treatment with TGF- $\beta$. In addition, fibroblasts derived from normal lungs were also sorted by FACS according to the expression of Thy-1. Sorted Thy-1 
$(+)$ and $(-)$ cells were cultured under standard conditions and at early confluence were changed to serum-free medium and stimulated with $5 \mathrm{ng} / \mathrm{ml}$ of TGF- $\beta$ for $48 \mathrm{~h}$. Cells were used for immunocytochemistry and CM were used for gelatin zymography.

\section{RESULTS}

Most fibroblasts Cultured from HP, IPF, and Normal Lungs Express Similar Levels of Thy-1, Despite Reduced Levels of mRNA in IPF Fibroblasts

To determine the percentage of Thy-1-expressing lung fibroblast derived from controls, HP, and, IPF patients, we carried out a FACS analysis. As illustrated in Figures 1a and b, in general, high proportions of Thy-1-positive fibroblasts
(75-95\%) were detected in all three groups without significant differences between groups. Fibroblasts from IPF were found to have significantly lower Thy-1 mRNA expression compared with control fibroblasts $(141 \pm 22.8$ versus $468 \pm 47.7 ; P<0.01$; Figure 1d). Unexpectedly, we found absent Thy-1 expression in a fibroblast primary cell-line obtained from a patient with HP (Figures $1 \mathrm{a}$ and $\mathrm{b}$ ). This patient was a 54-year-old female, who showed a moderate restrictive functional pattern at the time of diagnosis (forced vital capacity of 58\%) with hypoxemia at rest $(\mathrm{PaO} 2=60 \mathrm{~mm} \mathrm{Hg}$, normal values at the altitude of Mexico $\mathrm{DF}, 67 \pm 3 \mathrm{~mm} \mathrm{Hg}$ ), which worsened with exercise (resting SpO2 $90 \%$ and at the end of a 6-min walk, 81\%). Despite treatment with prednisone and azathioprine, the patient

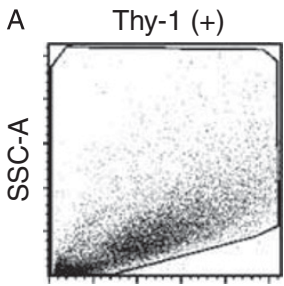

FSC-A

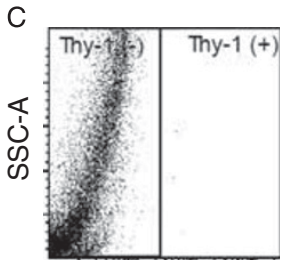

Thy-1 APC-A

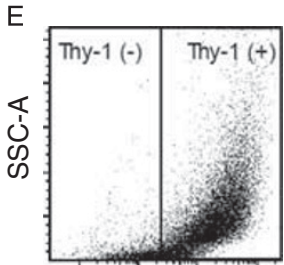

Thy-1 APC-A

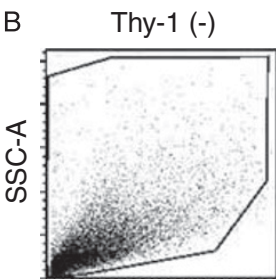

FSC-A

D

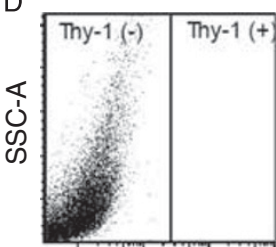

Thy-1 APC-A

$\mathrm{F}$

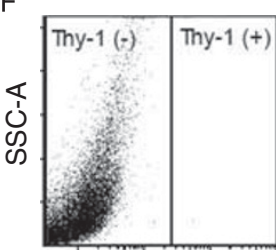

Thy-1 APC-A

c

$\mathrm{kDa}$

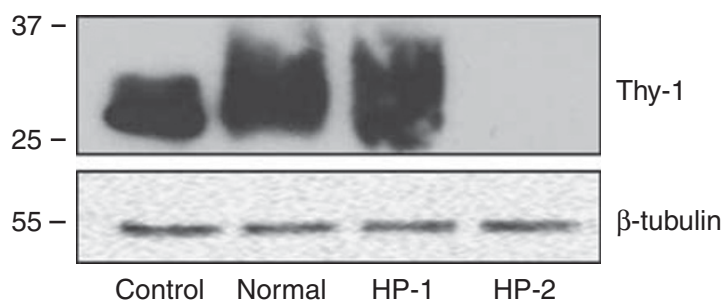

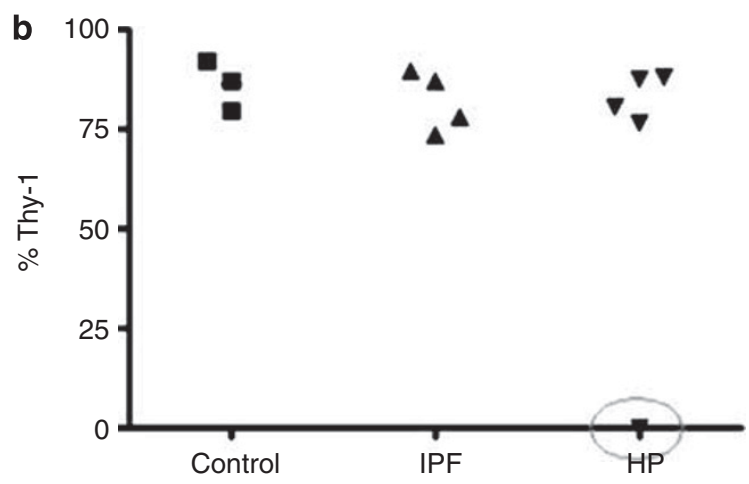

d

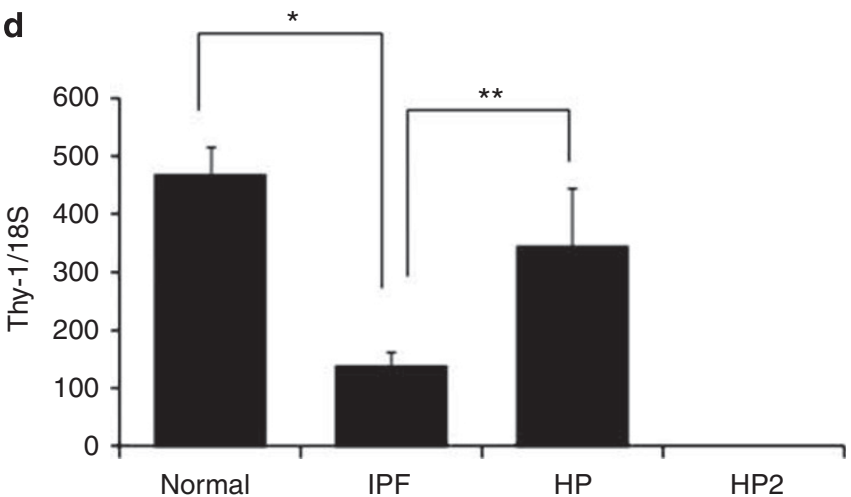

Figure 1 Thy-1 gene and protein expression in human lung fibroblasts. (a) Representative flow-cytometry analysis of lung fibroblast cell lines derived from two HP patients showing the expression and the absence of Thy-1. Forward scatter dot plot (A and B) shows the smaller size of the Thy-1 ( - ) cells. Panels $C$ and D show Thy-1-unstained fibroblasts; and E and F, Thy-1-stained fibroblasts. (b) Percentage of Thy-1 expression in three normal (control), 4 IPF, and 5 HP primary fibroblast cell-lines. The majority of the cell lines expressed Thy-1 except a fibroblast cell line derived from an HP patient. (c) Western blot for Thy-1 in the same fibroblasts used for gene expression. $\beta$-tubulin was used as house keeping gene. IMR-32 cell lysate (lane 1 ) was used as positive control. (d) Gene expression by quantitative real-time PCR showing samples from three normal, three IPF and two HP fibroblast lines analyzed in triplicate. Results were normalized with $18 \mathrm{~S}$ rRNA and are expressed as mean \pm s.d.; ${ }^{*}<0.01, * * P<0.05$. 


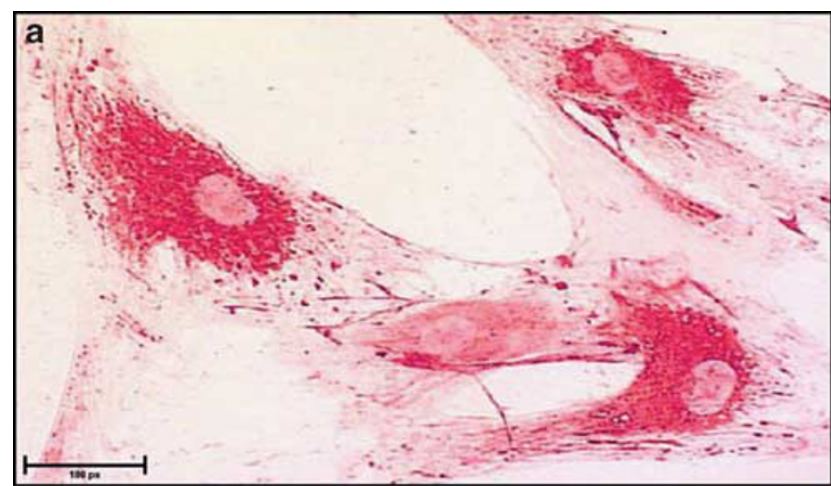

HP-1 [Thy-1 (+)]

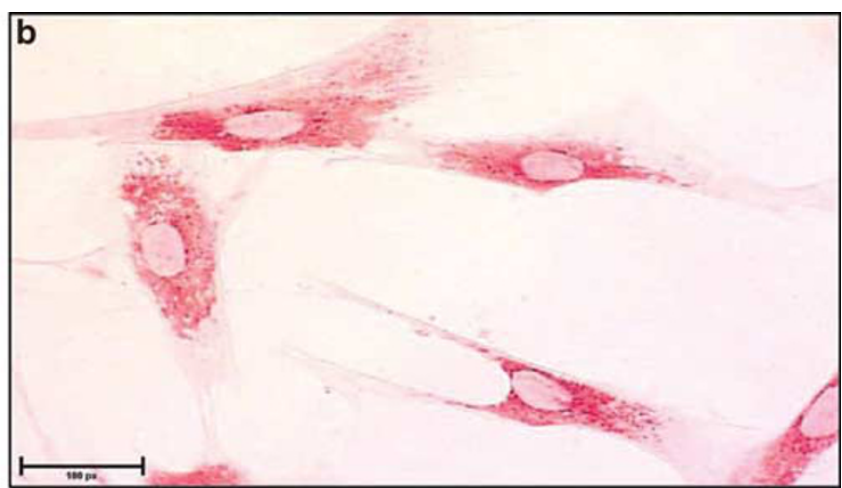

HP-2 [Thy-1 (-)]

Figure 2 Immunocytochemistry for pro-collagen I in Thy-1 (+) and (-) lung fibroblasts. (a) HP-1 Thy-1 (+) fibroblasts; (b) HP-2 Thy-1 (-) fibroblasts. Note that Thy-1 (-) cells are smaller than Thy-1 (+) lung fibroblasts. Magnification $60 \times$. Each bar represents $100 \mu \mathrm{M}$.

worsened and died 5 years after diagnosis. The absence of Thy- 1 expression at the mRNA and protein levels was confirmed by qRT-PCR and western blotting (Figures $1 \mathrm{c}$ and d). Thy-1-negative cells (named HP-2) appeared to be a population of smaller size than the Thy-1-positive fibroblasts as revealed by forward scatter in flow cytometry (Figure 1a, panels $\mathrm{A}$ and $\mathrm{B}$ ).

The smaller size of Thy-1 (-) fibroblasts was corroborated by microscopy as shown after collagen I immunostaining (Figure 2). Thy-1 (-) fibroblasts showed a twofold decreased length compared with the Thy-1-positive cells $(41.3 \pm 20.8 \mu$ versus $83.1 \pm 40 \mu$ ). No differences were found in vimentin, collagen, or TGF- $\beta$ expression between Thy-1 (-) and Thy-1 $(+)$ fibroblasts (not shown).

\section{Thy-1 Genomic Analysis}

Genomic DNA from Thy-1 $(+)$ and $(-)$ fibroblasts was used to analyze the presence or absence of Thy-1 gene. As shown in Figure 3a when analyzed by Southern blot there was hybridization with Thy-1 taqman probe in HP-1 fibroblasts. By contrast no hybridization was observed in HP-2 cells. This result was confirmed by PCR, in which Thy-1 product was amplified only in HP-1 cells and no amplification was observed in HP-2 fibroblasts (Figure 3b), indicating complete absence of the Thy-1 gene in this cell line. In addition, the lung tissue of these HP patients was analyzed by immunohistochemistry for Thy-1. As illustrated in Figure 3c no immunostaining was observed in HP-2 lung tissue (panels B, D), whereas HP-1 lung-tissue stained positive for Thy-1 in several cell types, for example, endothelial cells, and some interstitial cells (panels A, C).

\section{Thy-1 (-) Fibroblasts Show Increased Growth Rate}

Cell growth was examined in the Thy-1-negative fibroblasts and three Thy-1-positive fibroblast primary cultures from HP, IPF, and normal lungs, respectively, by using the WST-1 assay. As shown in Figure 4, Thy-1 (-) cells fibroblasts in the presence of $1 \%$ FBS, displayed a significant higher growth rate in comparison with different cultures of Thy-1 $(+)$ cells from the second day on.

\section{Thy-1 (-) Fibroblasts Exhibit Increased Migration Rate and In Vitro Wound Healing}

To analyze the effects of Thy-1 expression on fibroblast migration, we carried out a wound-healing scratch assay and a collagen transmigration assay using a Boyden chambers. As shown in Figure 5a HP-2 [Thy-1 (-)] fibroblasts closed the scratch wound more rapidly than HP-1 [Thy-1 $(+)]$ and closed the linear wounds at $60 \mathrm{~h}$. Likewise, cell transmigration through collagen I-coated Boyden chambers in response to PDGF-B was significantly higher in Thy-1 $(-)$ compared with Thy $(+)$ cells under basal conditions $(P<0.01)$. TGF- $\beta$ stimulation further increased Thy-1 ( -$)$ fibroblast transmigration $(P<0.05)$, whereas HP-1 [Thy-1 $(+)]$ cells showed no change (Figure $5 b)$.

\section{Thy-1 (-) Fibroblasts Induce A Strong Contraction of Collagen Matrices}

We examined the contraction of stress-relaxed collagen gels in HP-1 and HP-2 cells. Fibroblasts were incubated in collagen gels plated on rigid tissue-culture plastic for $2 \mathrm{~h}$. Thereafter, collagen gels were released from the dish (stress-relaxed gels), and gel diameter was photographed over time. As shown in Figure 6, under basal conditions Thy-1 (-) (HP-2) fibroblasts demonstrated a significant increase of collagen gel contraction compared with Thy-1 $(+)$ (HP-1) cells. This effect was further increased with TGF- $\beta$ stimulation (eg, $0.17 \pm 0.03$ versus $0.6 \pm 0.05 \mathrm{~cm}^{2}$ at $24 \mathrm{~h}$; $P<0.01)$.

\section{TGF- $\beta 1$ Induces the Expression of Mmp-9 in Thy-1 (-) Fibroblasts}

It is known that TGF- $\beta 1$, a major profibrotic mediator implicated in the pathogenesis of pulmonary fibrosis, induces the expression of MMP-9 in several cell types. Therefore, we tested the effect of TGF- $\beta 1$ on the expression of MMP- 2 and 
a

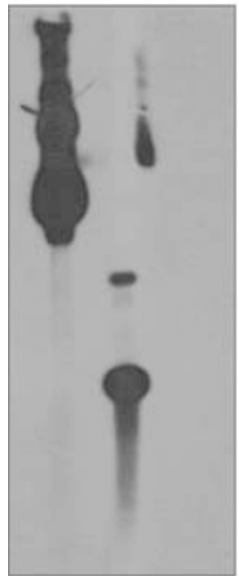

HP-1 HP-2

\section{b}

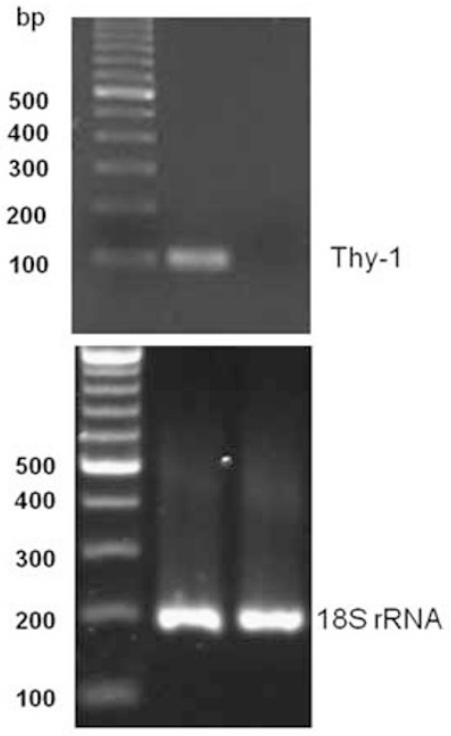

HP-1 HP-2
C
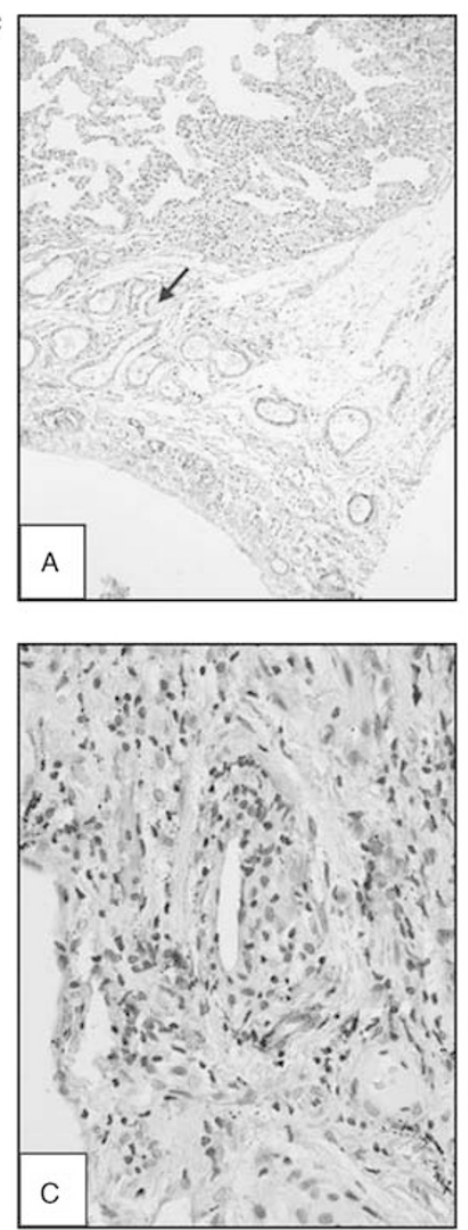

HP-1
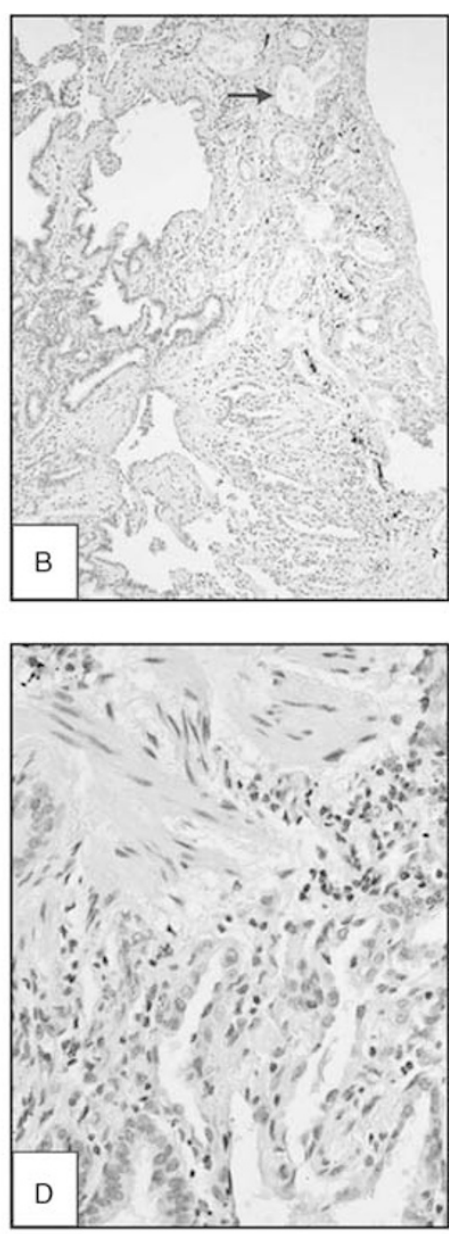

HP-2

Figure 3 Detection of Thy-1 gene. (a) Southern blot analysis of Thy-1 (+) and (-) fibroblasts. Genomic DNA was digested using Hindlll enzyme and the membrane was hybridized with a Thy-1 fragment. (b) Thy-1 PCR on genomic DNA from Thy-1 $(+)$ and $(-)$ fibroblasts. Thy- 1 product was amplified using a taqman probe. (c) Immunohistochemical analysis showing Thy-1 endothelial staining (panel A, arrow) and interstitial cells (panel C) in HP-1 lung tissue. No staining was observed in the HP-2 lung tissue. Magnification: $10 \times(A, C) ; 40 \times(B, D)$.

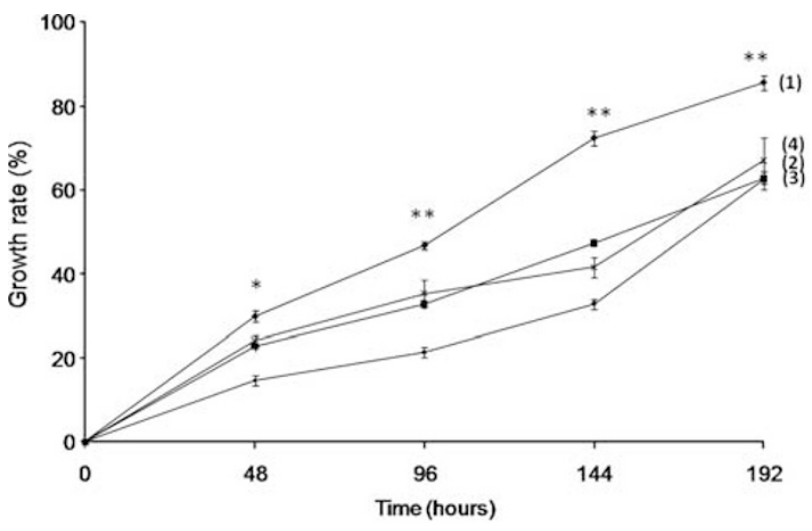

$\rightarrow(1) \mathrm{NH}$ Thy-1(-) $\quad-(2) \mathrm{NH}$ Thy-1(+) $\quad \rightarrow(3)$ FPI Thy-1(+) $\quad-(4)$ Normal Thy-1(+) $* * p<0.01$
$* p<0.05$

Figure 4 Fibroblast growth rate. Human lung fibroblasts were cultured in 96-well culture plates. At 2, 4, 6, and 8 days, growth rate was evaluated by WST-1 assay. Each point represents mean \pm s.d. of three independent experiments performed in triplicate.
MMP-9. Thy-1 (-) and Thy-1 (+) lung fibroblasts were cultured, stimulated with TGF- $\beta 1$ and MMP- 2 and MMP-9 were evaluated by gelatin zymography and immunocytochemistry. As illustrated in Figure $7 \mathrm{a}$, stimulation of Thy-1 (-) with TGF- $\beta 1$ induced the expression of MMP-9, a matrix-metalloproteinase that is usually not produced by lung fibroblasts, whereas no changes were observed in MMP-2. When we exposed the Thy-1 (-) fibroblasts to TGF$\beta$ RIII, a TGF- $\beta$ receptor antagonist also known as $\beta$-glycan, ${ }^{20}$ the MMP-9 activity band induced by TGF- $\beta 1$ was abolished (Figure $7 b$ ).

Immunocytochemical staining further corroborated the expression of the MMP-9 immuno-reactive protein in Thy-1 (-) fibroblasts. As shown in Figure 8a after TGF- $\beta 1$ stimulation, strong cytoplasmic MMP-9 staining is revealed in the Thy-1 (-) fibroblasts, whereas it was negative in the Thy-1 $(+)$ cells. It has been previously reported that fibroblastic foci in IPF lungs do not express Thy-1. ${ }^{9}$ Therefore, we explored by immunohistochemistry whether fibroblasts in 
a
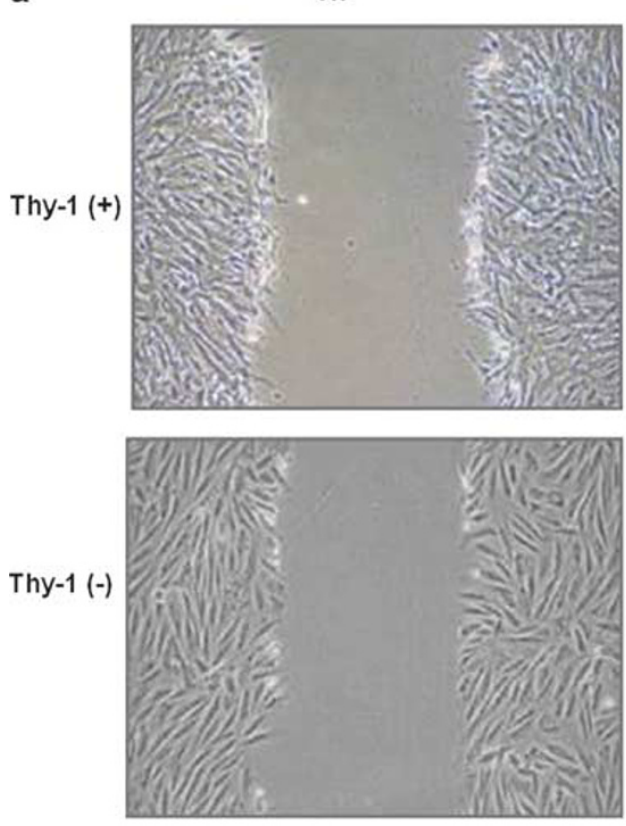

$24 \mathrm{~h}$
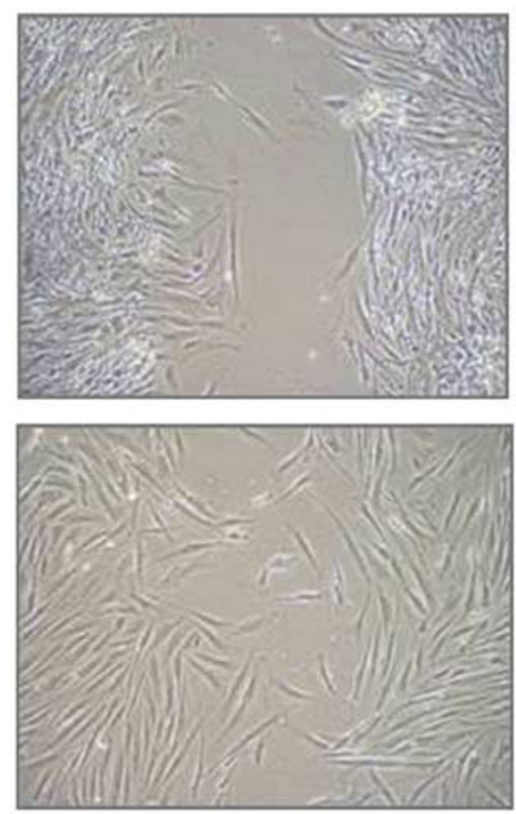

$60 \mathrm{~h}$
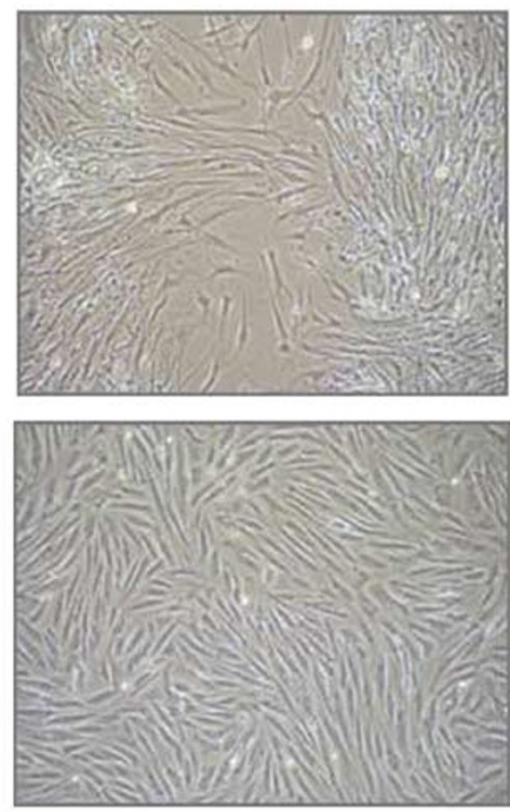

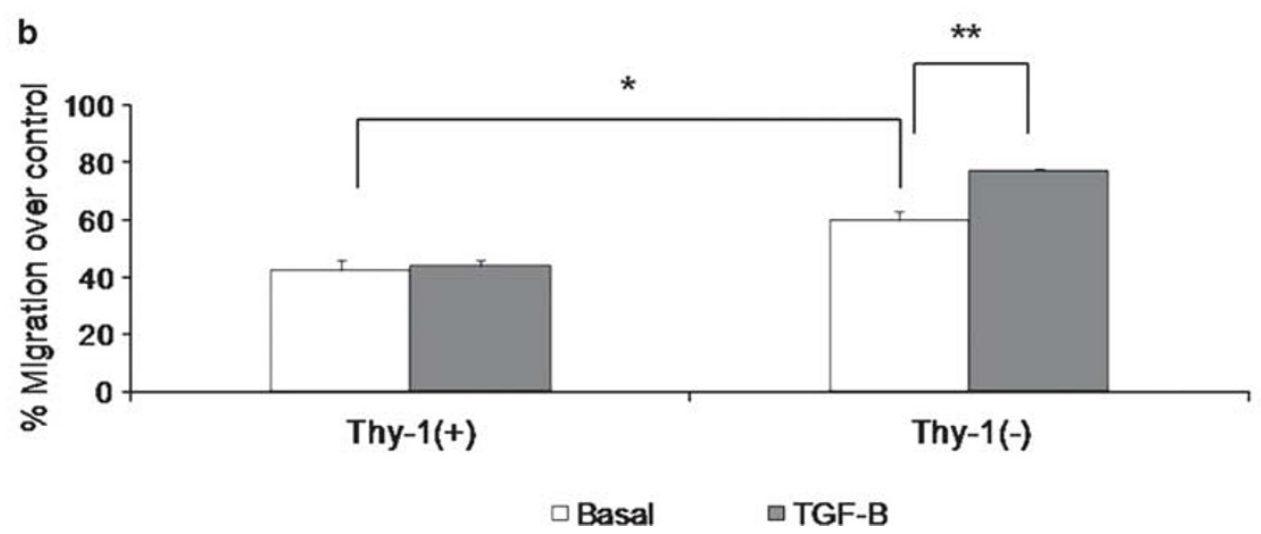

Figure 5 Fibroblast migration and collagen gel contraction assay. (a) Wound-healing scratch assay. Confluent monolayers of Thy 1 (+) and Thy $1(-)$ HP fibroblasts were mechanically disrupted with a sterile $200 \mu \mathrm{l}$ tip, then photographed immediately $(0 \mathrm{~h})$, or at the indicated hours after scratching. The assay was performed in duplicate. (b) Transmigration assay in collagen I-coated Boyden chambers, showing Thy-1 (+) and Thy-1 (-) fibroblasts in basal conditions and stimulated with TGF- $\beta$ PDGF-B was used as chemoattractant in the lower compartment. Each bar represents a duplicate experiment; ${ }^{*} P<0.01,{ }^{* *} P<0.05$.

these foci express MMP-9. As shown in Figure 8b, numerous fibroblasts in the fibroblastic focus exhibit intense MMP-9 staining. As earlier found, epithelial cells also revealed positive MMP-9 staining. ${ }^{18}$

Thy-1 Gene Transfection Inhibits TGF- $\beta 1$-Induced MMP-9 Lung Thy-1 (-) fibroblasts were transfected with the Thy-1 gene and then were sorted and re-analyzed by FACS to confirm Thy- 1 expression (Figure 9a). In all, $42 \%$ of Thy- $1(-)$ fibroblasts were transfected. After that, sorted (>95\%) Thy-1 $(-)$ and Thy-1 $(+)$ cells were plated and stimulated with TGF- $\beta(5 \mathrm{ng} / \mathrm{ml})$ for $24 \mathrm{~h}$, and CM were used to run a gelatin zymography. As shown in Figure 9b, the induction of MMP-9 by TGF- $\beta$ disappears with the re-expression of Thy- 1 . To further corroborate some of the characteristics of Thy-1 (-) cell line, fibroblasts derived from normal lungs were sorted on the basis of Thy- 1 expression. As shown in Figure 10a(B) Thy-1 (-)-sorted cells were smaller than Thy-1 $(+)$ fibroblasts. To evaluate the effect of TGF- $\beta$, Thy-1-positive and -negative cells were stimulated with the growth factor and the expression of MMP-9 was analyzed. In sorted Thy-1negative cells, TGF- $\beta$ induced the expression of MMP-9 as shown by gelatin zymography and immunocytochemistry (Figures 10b and c).

\section{TGF- $\beta 1$-Induces MMP-9 Expression Through p44 and p42 Extracellular Signal-regulated MAP Kinase (ERK1/2) Pathway}

It has been demonstrated that TGF- $\beta 1$ alone or in combination with epidermal growth factor (EGF) induces the 


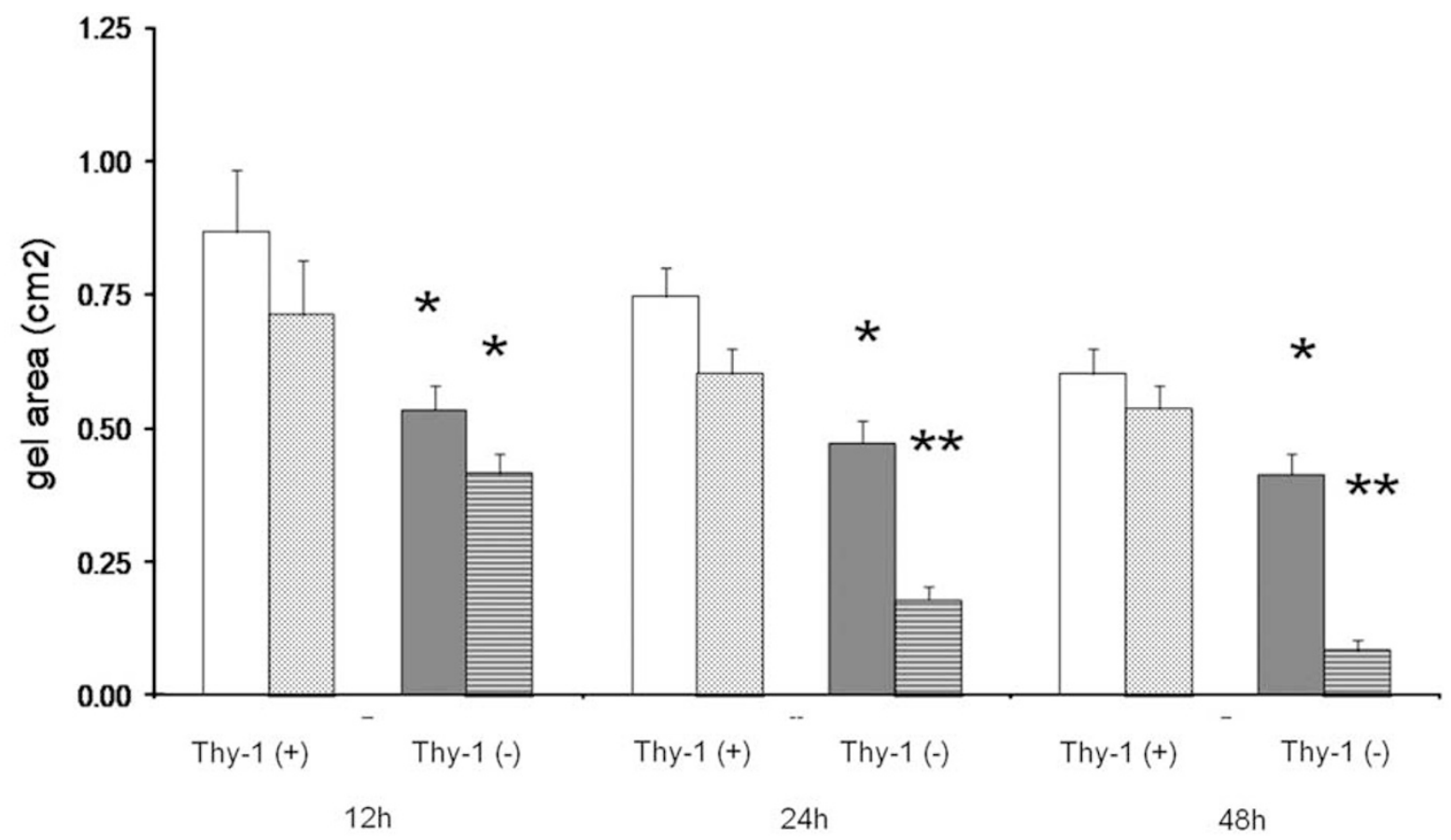

$0 \mathrm{~h}$

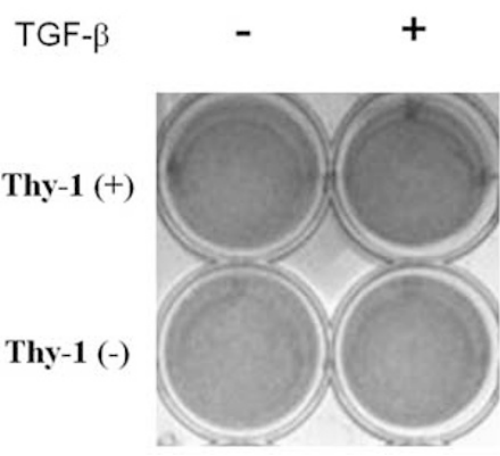

$12 \mathrm{~h}$

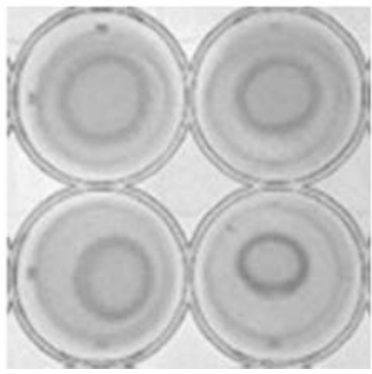

$24 \mathrm{~h}$

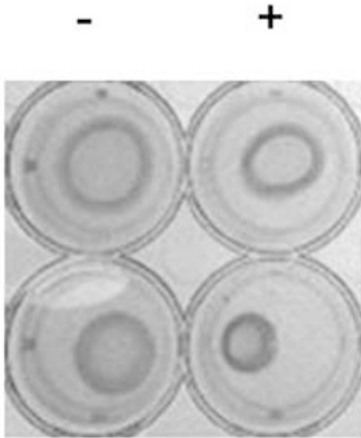

$48 \mathrm{~h}$

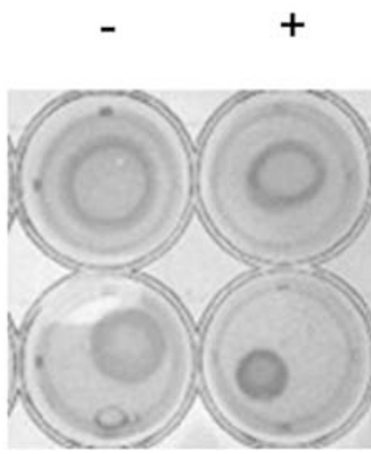

Figure 6 Collagen-gel contraction assay. Representative gels of floating-populated collagen matrices after 12, 24, and $48 \mathrm{~h}$ with serum-free Ham's F-12 medium or stimulated with TGF- $\beta(5 \mathrm{ng} / \mathrm{ml})$. Thy- $1(-)$ cells showed higher contractibility, than Thy $-1(+)$ cells. The graphic shows the gel area of the cells measured under basal and after TGF- $\beta$ stimulation. White bars represent Thy- $1(+)$ cells under basal conditions. Dotted bars represent same cells under TGF- $\beta$ stimulation. Gray bars show Thy-1 $(-)$ in basal conditions and bars with horizontal lines, same cells stimulated with TGF- $\beta$. ${ }^{*} P<0.05$; ${ }^{* *} P<0.01$ comparing Thy-1 (-) with Thy-1 $(+)$ fibroblasts under the same experimental conditions.

expression of MMP-9 through ERK activation. ${ }^{21}$ Both, Thy-1 $(-)$ and Thy-1 $(+)$ fibroblasts activate ERK after TGF- $\beta 1$ stimulation, although this effect was stronger in the Thy-1 (-) cells (Figures 11a and b). The use of PD98059, a pharmacological inhibitor of ERK, significantly reduced ERK phosphorylation (Figures 11a and b). We then investigated the effect of PD98059 on MMP-9 in gelatin zymography. As shown in Figure 11c, the ERK inhibitor abolished the MMP-9 activity band.

\section{DISCUSSION}

Lung fibrosis is a common consequence of a variety of injuries and is characterized by the expansion of the fibroblast population followed by the phenotypic transition to myofi- broblasts, accumulation of extracellular matrix, and loss of the normal architecture. IPF represents the most aggressive form of pulmonary fibrosis and is consequently the most studied fibrotic lung disorder. In this disease, it has been reported that fibroblasts obtained from the fibrotic areas display unique features that differentiate them from normal lung fibroblasts. ${ }^{5-8}$ One of them is the lack of expression by the fibroblasts/myofibroblasts in the fibroblastic foci of the receptor Thy-1, a glycosyl phosphatidylinositol (GPI)-linked cell surface glycoprotein, likely due to hypermethylation of cytosine-guanine islands in the gene promoter., 90 The Thy-1 (-) fibroblast subset seems to characterize a fibrogenic phenotype, although much of our knowledge about the putative differences between Thy-1 (-) and Thy-1 (+) 

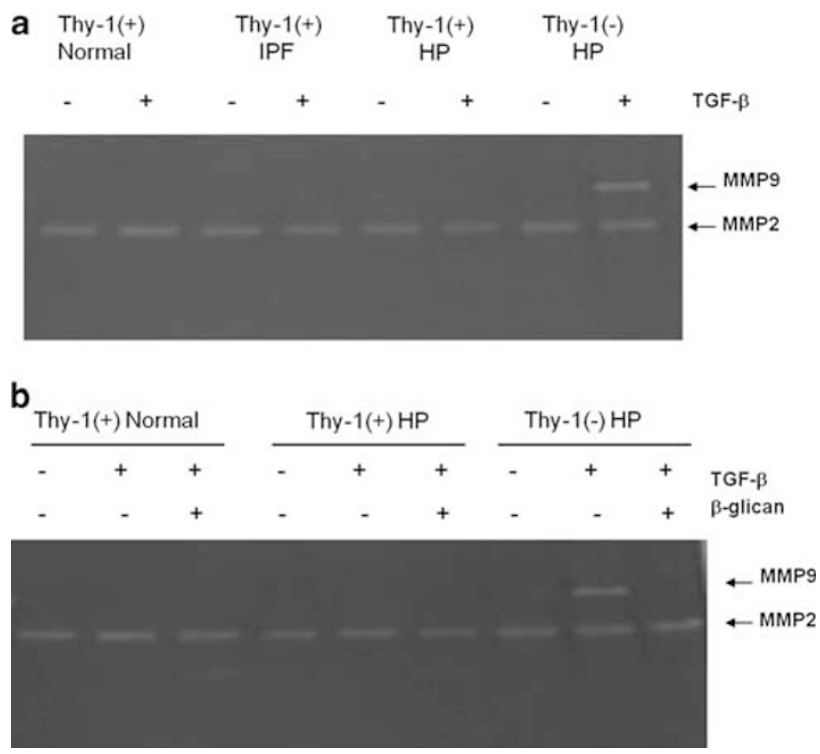

Figure 7 Gelatin zymography of lung fibroblasts stimulated with TGF- $\beta$. (a) Aliquots of conditioned media derived from lung fibroblasts with serum-free Ham's F-12 medium or stimulated for $24 \mathrm{~h}$ with TGF- $\beta$ $(5 \mathrm{ng} / \mathrm{ml})$ were subjected to $10 \%$ SDS-PAGE-containing gelatin.

(b) $\beta$-glican (a generous gift of Dr Lopez-Casillas; UNAM) blocked MMP-9 induction by TGF- $\beta$. fibroblasts is based on studies of rodent lungs. Rat-lung Thy-1 (-) fibroblasts respond to different stimuli by increasing TGF- $\beta$ activity, Smad3 phosphorylation, and expression of $\alpha$-SMA and fibronectin, whereas Thy- $1(+)$ fibroblasts resist stimulation. ${ }^{22,23}$ Likewise, Thy-1-deficient mice displayed more severe lung fibrosis and increased TGF$\beta$ activation that their wild-type littermates. ${ }^{9}$ However, the functional consequences of the absence of this receptor in the fibroblasts are not fully understood, and furthermore, studies in human lung fibroblasts have been limited.

In this study, we analyzed the expression of Thy- 1 in several primary fibroblast cultures derived from normal, HP and IPF lungs. In general, a high proportion of most of them independently of their origin (normal or pathologic lungs) expressed Thy- 1 in vitro. As fibroblasts from fibroblastic foci are Thy-1 (-) in IPF tissues, ${ }^{9}$ this finding may be counterintuitive; however, there are a number of potential explanations. Thy- 1 silencing in IPF is specific to fibroblastic foci. Fibroblasts in unaffected areas in IPF lungs, as well as in areas of dense collagenous fibrosis where myofibroblasts are less abundant express Thy-1 normally. ${ }^{9,10}$ Because IPF histopathology is heterogeneous, it is possible that isolated fibroblasts are obtained from areas with few or no fibroblastic foci. It is also possible that Thy-1 expression in primary cells
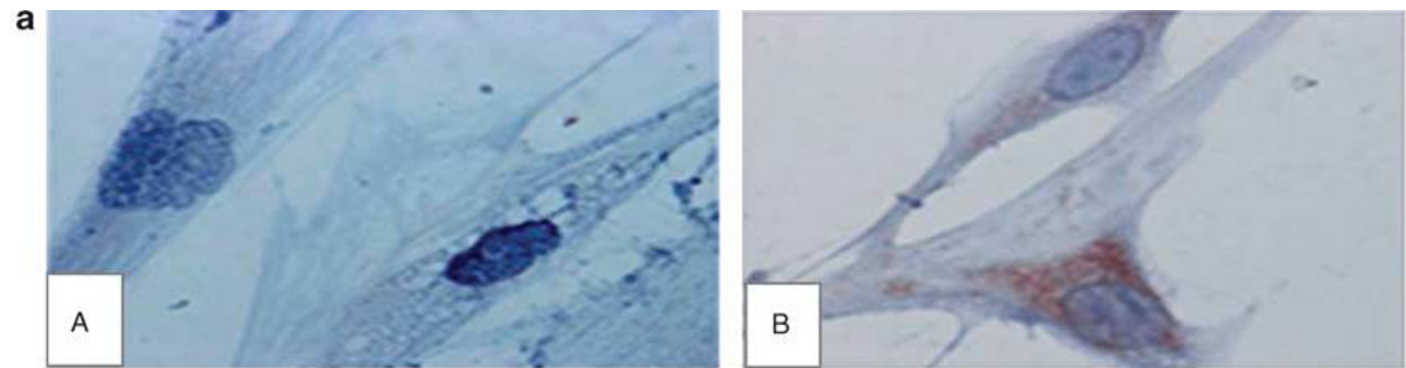

b
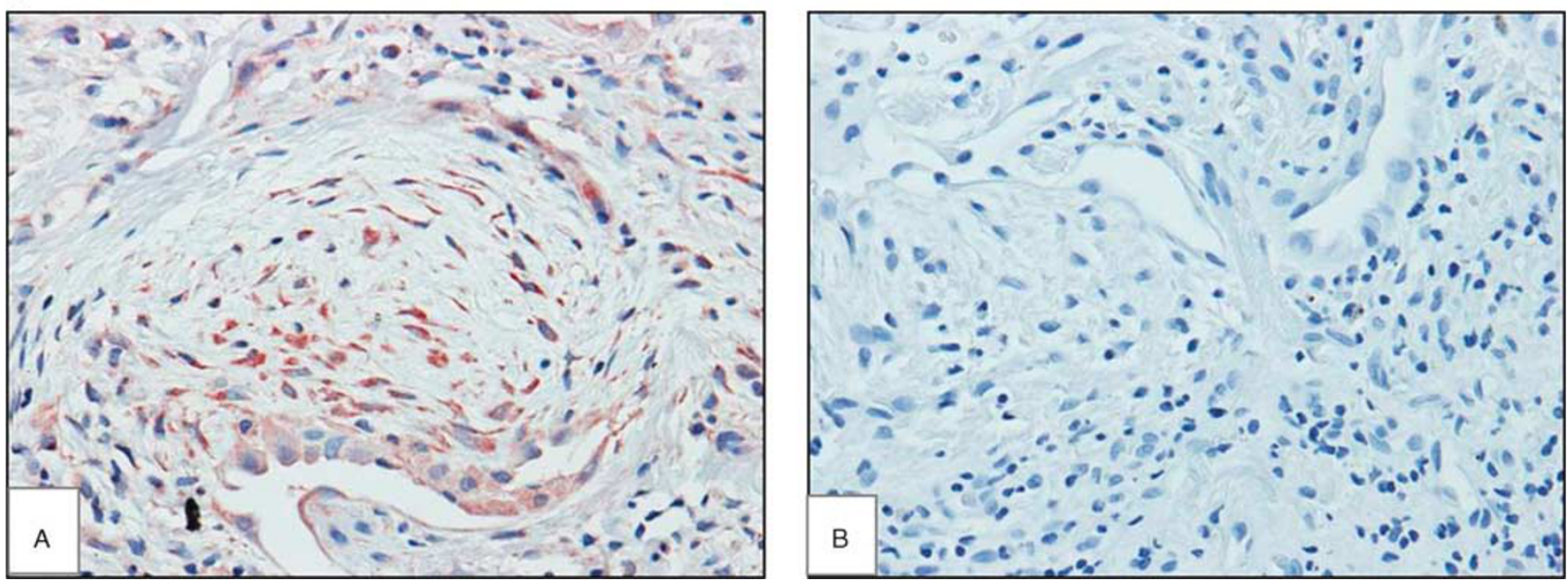

Figure 8 Cell and tissue localization of MMP9. (a) Representative immunocytochemistry of MMP9 expression in HP-1 Thy-1 (+) cells (A) and HP-2 Thy-1 (-) cells (B) stimulated with TGF- $\beta(5 \mathrm{ng} / \mathrm{ml})$ for $24 \mathrm{~h}$. (b) Immunohistochemistry of MMP9 in IPF lung tissue showing immunoreactive MMP9 in fibroblastic foci (A). Negative-control section from IPF lung, in which the primary antibody was omitted (B). Magnification $40 \times$. 

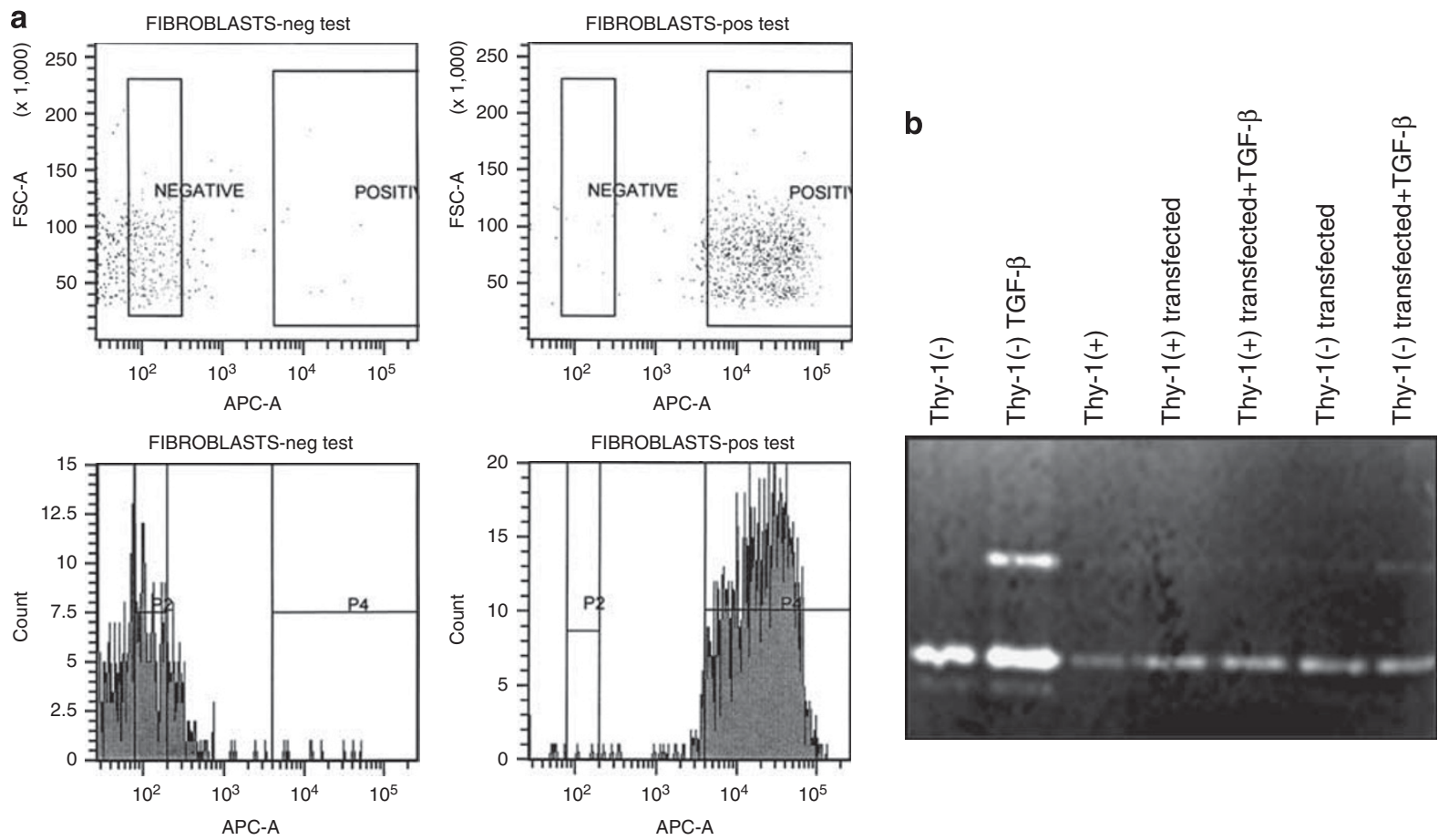

Figure 9 Thy-1-transfection. (a) Thy-1 (-) cells were transfected with Thy-1 and then sorted and retested for Thy-1 expression by FACS. Thy-1 ( + ) and ( - ) sorted cells were plated and stimulated with TGF- $\beta$ for $24 \mathrm{~h}$. (b) Gel zymography showing lack of MMP9 band activity in the cells, in which Thy- 1 is re-expressed. The non-transfected cells show MMP-9 activity under TGF- $\beta$ stimulation.

changes with time in culture, as the microenvironment differs greatly from that in vivo. Interestingly, both HP and IPF fibroblasts demonstrated significantly decreased Thy-1 mRNA, suggesting that perhaps mechanisms of Thy-1 silencing in vivo may still be present, although to a lesser degree, in vitro. We have demonstrated alterations in methylation of the Thy-1 promoter leading to silencing of Thy-1 within fibroblastic foci in IPF. ${ }^{10}$ More recently we have demonstrated regulation of Thy-1 expression by chromatin modifications such as alterations in histone acetylation and methylation, ${ }^{24}$ as well as interactions between chromatin modifications and DNA methylation, which could result in intermediate levels of Thy-1 mRNA expression, and alter the susceptibility to complete silencing within the microenvironment of fibrotic lesions. Fibroblast Thy-1 expression in HP has not been previously described.

Unexpectedly, we identified a primary culture of fibroblasts derived from a patient with HP, who died from lung fibrosis 5 years after diagnosis, which did not express the receptor Thy-1. Therefore, we were able to explore and compare several functional aspects between Thy-1 (-) and $(+)$ human lung fibroblasts. This finding represented an opportunity to explore the biology of a human Thy-1negative fibroblast cell line to better understand the role of this receptor in fibrotic lung disorders.

Thy-1 (-) fibroblasts were smaller and showed increased proliferative capacity and enhanced PDGF-induced transmigration through collagen I compared with the Thy-1 $(+)$ fibroblasts, two effects that are critical to wound healing and scar formation. Our results in the in vitro wound healing assay, which measures the average and directional migration of a cell population, and partially reflects also the growth rate was consistent with these findings, and with previous findings in rodent lung fibroblasts. ${ }^{25}$ Interestingly, Thy-1(-) fibroblast migration was further increased after TGF- $\beta 1$ stimulation, which may at least partially related to the expression of MMP-9.

We also found that Thy-1 (-) fibroblasts either spontaneously or after TGF- $\beta$ stimulation demonstrated a stronger contraction of collagen matrices, also consistent with findings in rodent cells. ${ }^{11}$ In this context, it has been recently demonstrated that Thy- 1 interacts with integrin $\alpha v \beta 5$ through an RGD-like motif, likely interfering with the binding of the latent TGF- $\beta 1$ complex. $^{22}$ This interaction inhibits latent TGF- $\beta 1$ activation and TGF- $\beta 1$-dependent fibroblast to myofibroblast differentiation.

The increased proliferative and migratory capacity and the strong induction of collagen matrix contraction support the notion that the absence of Thy-1 $(-)$ induces a fibrogenic phenotype in fibroblasts, and indicate that the mesenchymal cells in the fibroblastic foci, which are Thy-1 (-), have a higher fibrogenic potential.

Thy-1 (-) fibroblasts stimulated with TGF- $\beta 1$ express MMP-9, whereas Thy-1 $(+)$ lung fibroblasts under the same stimulus do not. Moreover, treatment of Thy-1 (-) fibroblasts with $\beta$-glycan, which is believed to sequester TGF- $\beta$, 
a

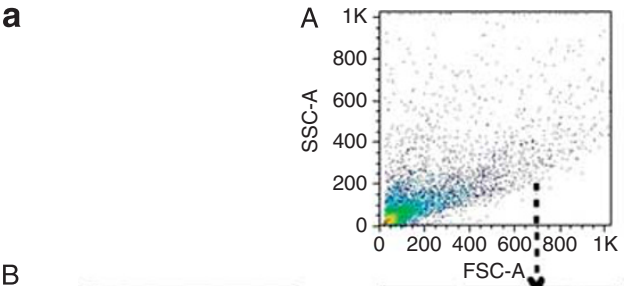

B b

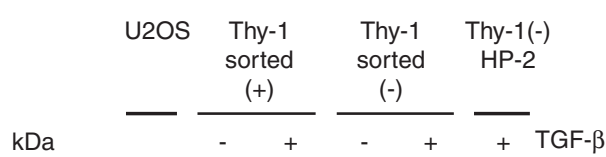

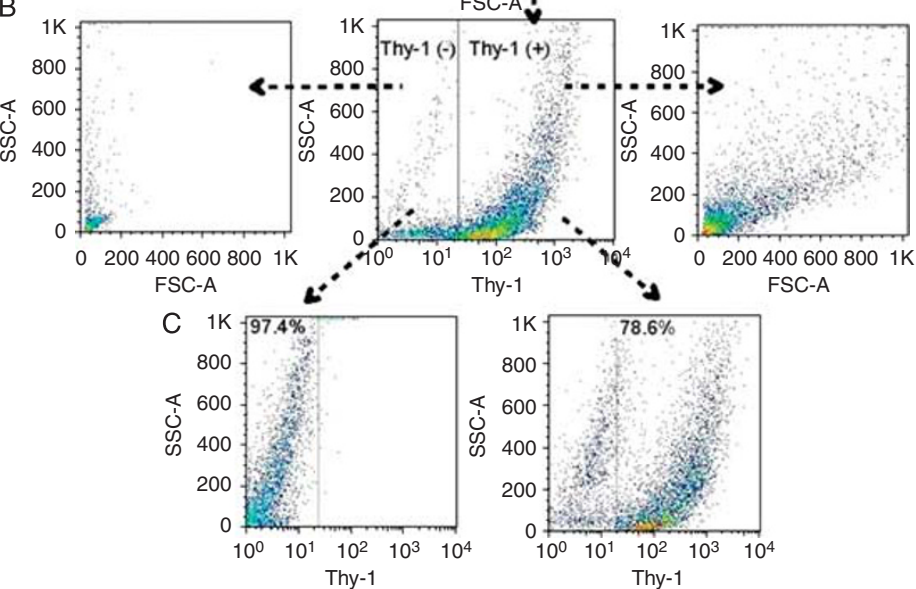

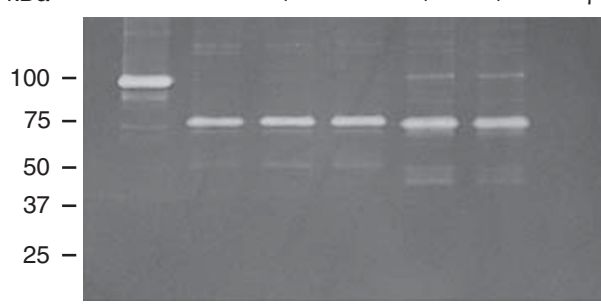

C

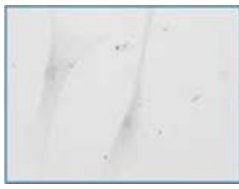

Thy-1 (+) sorted cells + TGF- $\beta$

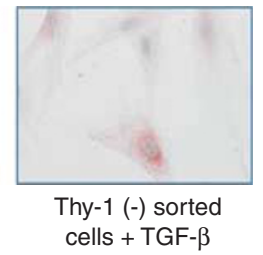

Figure 10 MMP-9 expression in Thy-1 $(+)$ and Thy-1 (-)-sorted fibroblasts derived from normal human lungs. (a) Flow-cytometry dot plots of cells stained and sorted on the basis of Thy-1 expression. The pseudo-color plot in (A) show the forward- and side-scatter characteristics of whole population; (B) sorted fibroblasts (center panel); Thy-1 (-)-sorted cells (backgating left panel) and Thy-1 (+)-sorted cells (backgating right panel); (C) fibroblasts retested on Thy-1 expression after sorting and growth in culture. Numbers in each gate indicate percentage of Thy-1 expression by each sub-population from a representative experiment. (b) Gelatin zymography of Thy-1 $(+)$ and (-) fibroblasts stimulated with TGF $\beta$. Osteosarcoma-derived U2OS cell line was used as positive control for MMP-9. (c) Immunoreactive MMP-9 in Thy-1 (+) and (-) sorted fibroblasts.
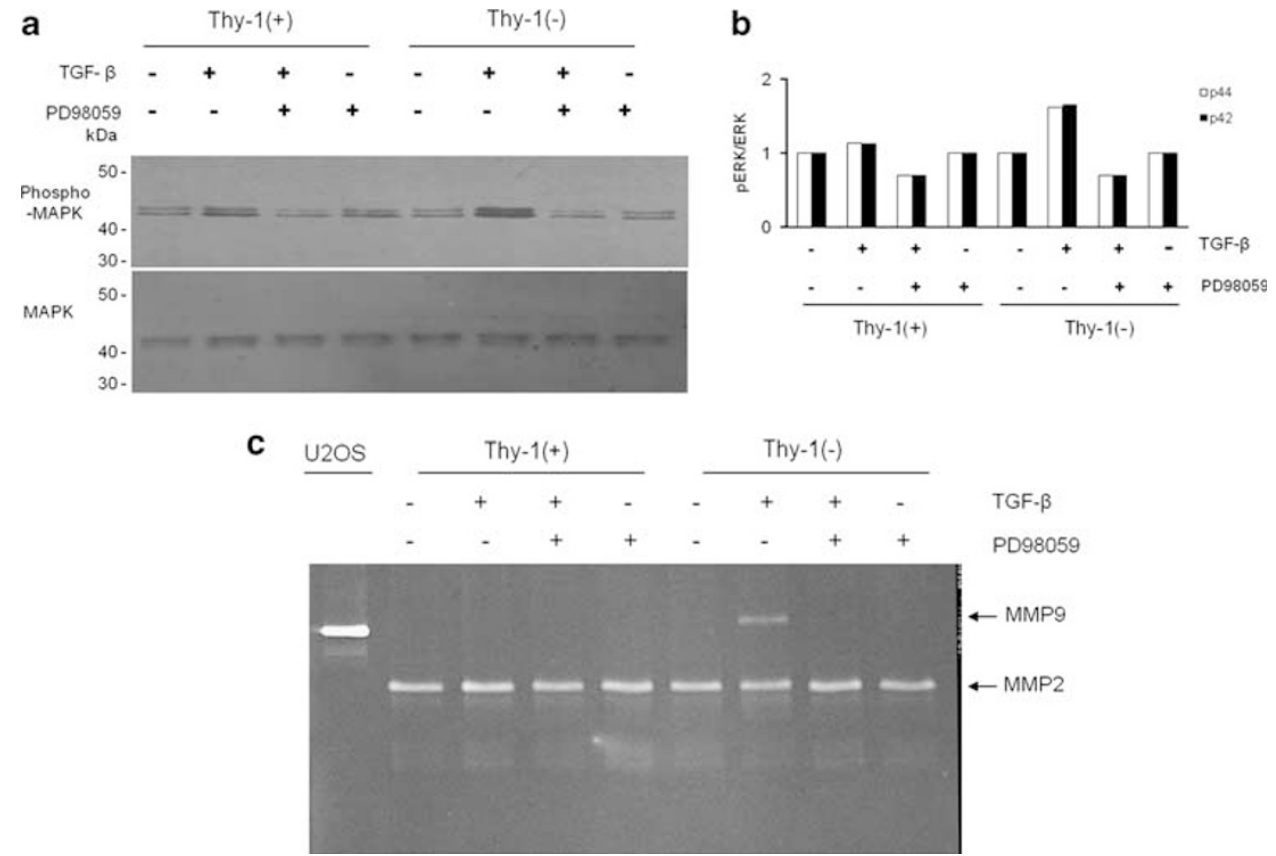

Figure 11 TGF- $\beta$ induces MMP-9 expression in Thy-1 (-) cells through ERK pathway. (a and b) Thy-1 (-) cells exhibited higher p42 and p44 MAPK phosphorylation in response to TGF- $\beta$ stimulation, which was inhibited by PD98059 a specific inhibitor of ERK pathway. (c) Gelatin zymography demonstrating absence of MMP9 induction by TGF- $\beta$ when ERK phosphorylation is inhibited. 
thereby functioning as a receptor antagonist, ${ }^{20}$ abolished MMP-9 induction. Importantly, we also found that fibroblasts from IPF fibroblastic foci, which do not express Thy-1 exhibit strong staining for the immunoreactive MMP-9 protein in vivo. These data suggest that in the fibroblastic foci in vivo, fibroblasts have lost Thy- 1 expression, ${ }^{9}$ likely allowing the activation of the latent TGF- $\beta 1$, which in turn, among a variety of profibrotic effects may induce the expression of MMP-9 as demonstrated in this study.

To further prove that the lack of expression of Thy- 1 was related to the expression of MMP-9, we transfected the Thy- 1 (-) fibroblasts with full-length Thy-1, and then sorted the cells. After sorting, the Thy-1-transfected fibroblasts lost the capacity to respond to TGF $-\beta 1$ with induction of MMP-9.

Transcriptional regulation is the rate-limiting step in MMP-9 synthesis and the cis-acting elements found in the human MMP-9 promoter include AP-1, NF- $\kappa \mathrm{B}, \mathrm{Sp} 1$, and Ets-1 binding sites. ${ }^{14,26}$ In addition, the coordination of cell signaling including the ERK pathway as found in this work, as well as chromatin remodeling, histone modifications, and the stepwise recruitment of transcription regulators has been shown to be critical to the regulation of MMP-9 gene expression. ${ }^{27}$

It was previously demonstrated that the co-stimulation of HK-2 cells, an immortalized human proximal tubular epithelial cell line, with EGF and TGF- $\beta 1$ increases cell migration, which is associated with a synergistic increase of MMP9 activity. ${ }^{21}$ The use of EGF and TGF- $\beta 1$ in this epithelial cell line led to an early and pronounced activation of ERK indicating that the downstream pathways of both growth factors converged on the ERK signaling pathway to influence MMP-9 expression and cell migration. Other reports also indicate that the MMP9 gene promoter is partially regulated through activation of the ERK1/2 pathway. Thus, it was demonstrated that interfering ERK1 signaling, either with PD 098059 or with a dominant negative expression construct, reduces $92 \mathrm{kDa}$ gelatinolysis and MMP-9 promoter activity, respectively. ${ }^{28}$ Likewise, it has been shown that the activation of FAK in A549 lung epithelial cells activates ERK1/2/MMP9 pathway to promote cell migration and invasion. ${ }^{29}$

In this study, we demonstrated that the mechanism by which TGF- $\beta 1$-induced MMP-9 in lung Thy-1 (-) fibroblasts also depends on the activation of ERK1/2 signaling pathway. Phosphorylation of ERK occurred in response to TGF- $\beta 1$ in both Thy-1 (-) and Thy-1 (+) fibroblasts but was stronger in the former, and importantly, PD98059, a specific pharmacological inhibitor of ERK, reduced ERK phosphorylation and abolished the expression of MMP-9. Interestingly, Thy-1 (-) mouse embryonic fibroblasts show increased TNF- $\alpha$-induced MMP-9 expression, which is mediated by Src-family kinase activation. ${ }^{30}$

MMP-9 (gelatinase B), has been proposed to have an important role in the pathogenesis of IPF. Increased synthesis and activation has been found in this disease associated with the degradation of collagen IV, a main component of the basement membrane. ${ }^{14}$ However, MMPs, in addition to their ability to cleave extracellular matrix proteins, also regulate the availability and function of cytokines and growth factors through sequence-specific cleavage. ${ }^{26}$ Importantly, MMP-9 proteolytically activates TGF- $\beta$ contributing to enhance the pool of active TGF- $\beta$ in the microenvironment. ${ }^{31}$ Thus, TGF$\beta$ induction of MMP-9 in Thy-1 (-) fibroblasts could be part of a fibrogenic positive feedback loop.

In summary, our results show that a lung fibroblast cell line lacking Thy-1 exhibits a high proliferative and migratory capacity, stronger contraction of collagen matrices, and importantly TGF- $\beta$-induced MMP-9 expression, reversible upon re-expression of Thy-1. Further studies are needed to understand the molecular mechanisms by which Thy- 1 modulates responsiveness to TGF $\beta$ and MMP-9 expression in lung fibroblasts.

\section{ACKNOWLEDGEMENT}

Partially supported by Grants: PAPIIT, IN203709, UNAM, and NIH HL082818 (to JSH).

\section{DISCLOSURE/CONFLICT OF INTEREST}

The authors declare no conflict of interest.

1. Selman M, King TE, Pardo A. Idiopathic pulmonary fibrosis: prevailing and evolving hypotheses about its pathogenesis and implications for therapy. Ann Intern Med 2001;134:136-151.

2. Hardie WD, Glasser SW, Hagood JS. Emerging concepts in the pathogenesis of lung fibrosis. Am J Pathol 2009;175:3-16.

3. Gross TJ, Hunninghake GW. Idiopathic pulmonary fibrosis. N Engl J Med 2001;345:517-525.

4. Hinz B, Phan SH, Thannickal VJ, et al The myofibroblast: one function, multiple origins. Am J Pathol 2007;170:1807-1816.

5. Ramos C, Montano M, Garcia-Alvarez J, et al Fibroblasts from idiopathic pulmonary fibrosis and normal lungs differ in growth rate, apoptosis, and tissue inhibitor of metalloproteinases expression. Am J Respir Cell Mol Biol 2001;24:591-598.

6. Moodley YP, Scaffidi AK, Misso NL, et al Fibroblasts isolated from normal lungs and those with idiopathic pulmonary fibrosis differ in interleukin-6/gp130-mediated cell signaling and proliferation. Am J Pathol 2003;163:345-354.

7. Phan SH. Biology of fibroblasts and myofibroblasts. Proc Am Thorac Soc 2008;5:334-337.

8. Larsson O, Diebold D, Fan D, et al Fibrotic myofibroblasts manifest genome-wide derangements of translational control. PLoS One 2008;3:e3220.

9. Hagood JS, Prabhakaran P, Kumbla P, et al Loss of fibroblast Thy-1 expression correlates with lung fibrogenesis. Am J Pathol 2005; 167:365-379.

10. Sanders $Y Y$, Pardo $A$, Selman $M$, et al Thy-1 promoter hypermethylation: a novel epigenetic pathogenic mechanism in pulmonary fibrosis. Am J Respir Cell Mol Biol 2008;39:610-618.

11. Sanders YY, Kumbla P, Hagood JS. Enhanced myofibroblastic differentiation and survival in Thy-1(-) lung fibroblasts. Am J Respir Cell Mol Biol 2007;36:226-325.

12. Bradley JE, Ramirez G, Hagood JS. Roles and regulation of Thy-1, a context-dependent modulator of cell phenotype. Biofactors 2009:35:258-265.

13. Rege TA, Hagood JS. Thy-1, a versatile modulator of signaling affecting cellular adhesion, proliferation, survival, and cytokine/growth factor responses. Biochim Biophys Acta 2006;1763:991-999.

14. Pardo A, Selman M. Matrix metalloproteases in aberrant fibrotic tissue remodeling. Proc Am Thorac Soc 2006;3:383-388.

15. Selman M, Pardo A, Barrera L, et al Gene expression profiles distinguish idiopathic pulmonary fibrosis from hypersensitivity pneumonitis. Am J Respir Crit Care Med 2006;173:188-198. 
16. Vilchis-Landeros MM, Montiel JL, Mendoza V, et al Recombinant soluble betaglycan is a potent and isoform-selective transforming growth factor- $\beta$ neutralizing agent. Biochem J 2001;355:215-222.

17. Ramos $C$, Montaño $M$, Becerril $C$, et al Acidic fibroblast growth factor decreases alpha-smooth muscle actin expression and induces apoptosis in human normal lung fibroblasts. Am J Physiol Lung Cell Mol Physiol 2006;291:L871-L879.

18. Selman M, Ruiz V, Cabrera $S$, et al TIMP-1, -2, -3, and -4 in idiopathic pulmonary fibrosis. A prevailing nondegradative lung microenvironment? Am J Physiol Lung Cell Mol Physiol 2000;279:L562-L574.

19. Pardo A, Gibson K, Cisneros J, et al Upregulation and profibrotic role of osteopontin in human idiopathic pulmonary fibrosis. PLoS Med 2005;2:e251

20. Lopez-Casillas F, Cheifetz S, Doody J, et al Structure and expression of the membrane proteoglycan betaglycan, a component of the TGFbeta receptor system. Cell 1991;67:785-795.

21. Tian YC, Chen YC, Chang CT, et al Epidermal growth factor and transforming growth factor-beta1 enhance HK-2 cell migration through a synergistic increase of matrix metalloproteinase and sustained activation of ERK signaling pathway. Exp Cell Res 2007;313: 2367-2377.

22. Zhou Y, Hagood JS, Murphy-Ullrich JE. Thy-1 expression regulates the ability of rat lung fibroblasts to activate transforming growth factorbeta in response to fibrogenic stimuli. Am J Pathol 2004;165:659-669.

23. Zhou Y, Hagood JS, Lu B, et al Thy-1-integrin alphavbeta5 interactions inhibit lung fibroblast contraction-induced latent TGF-beta1 activation and myofibroblast differentiation. J Biol Chem 2010;285:22382-22393.
24. Sanders YY, Tollefsbol TO, Varisco BM, et al Epigenetic Regulation of Thy- 1 by Histone Deacetylase Inhibitor in Rat Lung Fibroblasts. Am J Respir Cell Mol Biol; 19 August 2010 (e-pub ahead of print).

25. Barker TH, Grenett HE, MacEwen MW, et al Thy-1 regulates fibroblast focal adhesions, cytoskeletal organization and migration through modulation of p190 RhoGAP and Rho GTPase activity. Exp Cell Res 2004;295:488-496.

26. Fanjul-Fernández $M$, Folgueras $A R$, Cabrera $S$, et al Matrix metalloproteinases: Evolution, gene regulation and functional analysis in mouse models. Biochim Biophys Acta 2010;1803:3-19.

27. Ma Z, Shah RC, Chang MJ, et al Coordination of cell signaling, chromatin remodeling, histone modifications, and regulator recruitment in human matrix metalloproteinase 9 gene transcription. Mol Cell Biol 2004;24:5496-5509.

28. Gum R, Wang $H$, Lengyel $E$, et al Regulation of $92 \mathrm{kDa}$ type IV collagenase expression by the jun aminoterminal kinase- and the extracellular signal-regulated kinase-dependent signaling cascades. Oncogene 1997;14:1481-1493.

29. Meng $X N$, Jin $Y, Y u Y$, et al Characterisation of fibronectin-mediated FAK signalling pathways in lung cancer cell migration and invasion. $\mathrm{Br}$ J Cancer 2009;101:327-334.

30. Shan B, Hagood JS, Zhuo Y, et al Thy-1 attenuates TNF-alpha-activated gene expression in mouse embryonic fibroblasts via Src family kinase. PLoS One 2010;5:e11662.

31. Yu Q, Stamenkovic I. Cell surface-localized matrix metalloproteinase- 9 proteolytically activates TGF-b and promotes tumor invasion and angiogenesis. Genes Dev 2000;14:163-176. 